Cadernos de

Pesquisa do CDHIS

\title{
Uma Escola, um Marechal e uma Experiência Pedagógica sobre Educação Patrimonial
}

\author{
A School, a Marshal and a Pedagogical Experience About \\ Heritage Education
}

Talita Seniuk ${ }^{1}$

\footnotetext{
${ }^{1}$ Especialista em Metodologia do Ensino de História pelo Centro Universitário de Maringá e Especialista em Ensino de Sociologia pela Universidade Cândido Mendes, graduada em História pela Universidade Estadual de Ponta Grossa e em Ciências Sociais pela Universidade Metodista de São Paulo. Professora de História, Sociologia e Filosofia da Secretaria de Estado de Educação de Mato Grosso. E-mail: tltsnk@yahoo.com.br e talitaseniuk@gmail.com.
} 


\section{RESUMO}

Partindo-se da premissa de que a educação formal, que é desenvolvida nas instituições escolares deve dialogar com a realidade circundante para não se tornar um elemento alheio às necessidades locais de que poderia intervir e que sua função social extrapola seus muros, este artigo apresenta uma experiência pedagógica realizada numa escola pública estadual no ano letivo de 2019, considerando a proximidade do objeto estudado e as características da comunidade escolar na temática de educação patrimonial, efetivada numa oficina de História com alunos do Ensino Fundamental II. Posteriormente, apontam-se algumas percepções sobre o desenrolar da atividade e seu produto, comparados com os objetivos propostos e facilitados por tal metodologia, que atende aos pressupostos da Base Nacional Comum Curricular que permeia competências e habilidades considerando o desenvolvimento dos estudantes em todas as suas dimensões numa educação integral que prepara para os desafios da vida contemporânea.

\section{Palavras-chave: Educação} patrimonial. Função social da escola, Oficina de História, Patrimônio histórico-cultural.

\section{ABSTRACT}

Based on the premise that formal education, which is developed in school institutions, must dialogue with the surrounding reality so as not to become an element outside the local needs from which it could intervene and that its social function goes beyond its walls, this article presents a pedagogical experience conducted in a state public school in the school year 2019, considering the proximity of the object studied and the characteristics of the school community in the theme of heritage education, held in a History workshop with Elementary School students. Subsequently, some perceptions about the development of the activity and its product are pointed out, compared with the objectives proposed and facilitated by such methodology, which meets the assumptions of the Common National Curriculum that permeates competences and skills considering the development of students in all its dimensions in an integral education that prepares for the challenges of contemporary life.

Keywords: Heritage education. School's social function. History worshop. Historical-cultural heritage. 


\section{Educação formal}

A escola há milênios têm se mostrado como o lócus privilegiado do conhecimento; sua presença nas mais diversas culturas sempre se moldou para atender aos anseios da sociedade em que estava inserida. Durante muito tempo foi uma das únicas maneiras de um indivíduo adquirir erudição e dessa forma, seu acesso era elitizado; atualmente ainda não se apresenta como universal, mas muitos obstáculos têm sido derrubados para que alcance cada vez mais pessoas. Não restam dúvidas da importância dessa instituição em relação à sua função frente à humanidade, mas contemporaneamente tem se discutido que ela não se mostra mais como a única detentora do saber, acumulado através dos tempos pelas gerações anteriores. $\mathrm{O}$ ato de educar extrapola um único ambiente e se efetiva de diversas formas e em diferentes lugares; nesse sentido temos a escola e sua atuação como representante de uma educação formal, orientada, pautada no desenvolvimento do estado físico, intelectual e moral de seus tutelados e de outro lado, a informal, uma educação que acontece fora dela, pela família e comunidade, almejando os processos de socialização (LAKATOS; MARCONI, 2014), fundamentais para a vivência desse mesmo sujeito.

Não obstante a educação acontecer em diversos locais, cada uma com suas particularidades e objetivos, "a escola continua a ser um espaço de enorme importância para amplos setores da população que não possuem biblioteca, laboratório e computadores em casa - a maior parte da população..." (SILVA; FONSECA, 2010, p. 30). Tratando-se então da educação formal, sua complexidade de conteúdos se divide de modo disciplinar, cada uma com suas especificidades, sendo uma delas a História. Sua função extrapola os muros escolares, pois adquire "funções de orientação existencial" (RÜSEN, 2001, p. 34) ao aluno, que munido do conhecimento histórico pode nortear suas reflexões e ações em sua vida enquanto 
cidadão. É através dela que se podem perceber as relações de inúmeros grupos humanos, cada qual com sua cultura singular em períodos temporais e espaços diversos; essa dinamicidade mostra-a enquanto uma ciência em constante construção, em processos de metamorfose a cada nova nuance que emerge e permite compreender todos enquanto protagonistas de sua história.

Para subsidiar a articulação deste artigo, fora selecionada uma literatura que permeia práticas educacionais voltadas ao ensino de História em seus diversos matizes, uma vez que a pluralidade de fontes e metodologias inunda o cenário docente e nesse sentido, uma orientação teórica apresenta-se como essencial; autores como Brodbeck (2012), Figueira e Miranda (2012), Silva e Porto (2012), Ferreira e Franco (2013) atendem a essa demanda. Teremos ainda Schmidt (2008), Neves (1997), Bloch (2001), Braudel (1990), Karnal (2003), Certeau (1982), Scarpato (2004), Burke (2004), Oriá (2008), Bittencourt (2008) que contemplam conceitos chave na dimensão que abrange a área de Ciências Humanas e seus vieses. Levando-se em consideração a função social da escola, que busca o diálogo do educando com a sua realidade circundante, é possível progredir na metodologia de ensino de História de forma a contribuir mais empiricamente com a formação de cidadãos conscientes de seus papéis dentro de uma sociedade. Por isso, o artigo tem por finalidade relacionar os princípios da função social da escola com a educação patrimonial, com foco no estudo de caso da aplicação de uma oficina numa escola pública do Estado de Mato Grosso.

\section{Função social da escola}

Buscando atender as constantes demandas da sociedade no que tange a educação e a função social da escola, nas últimas décadas muitas metodologias e abordagens têm emergido com um único fim: o aprimoramento do aprendizado para que se torne efetivo ao aluno. Muito se tem discutido e implantado por vezes, nas 
políticas públicas que orientam o processo de ensino-aprendizagem, como na Lei de Diretrizes e Bases da Educação - LDB datada de 1996 e ainda vigente, os Planos de Educação em suas esferas nacional, estaduais e municipais que se moldam as especificidades locais e regionais e recentemente, na implantação da Base Nacional Comum Curricular - BNCC no Ensino Fundamental, que são referenciais para a prática docente em seus respectivos cenários. Há de se ressaltar que todos esses documentos, entre outros complementares, vêm sendo lapidados através dos tempos visando contemplar uma abordagem pautada na integralidade do ser humano enquanto ser social, desvinculando-se de uma ideia de conhecimentos fragmentados, valorizando as experiências de cada um e a complexidade da teia social em que estamos inseridos.

A LDB já contemplava em seu artigo 26 que o currículo escolar deve ser complementado por uma parte diversificada considerando as características regionais e locais da sociedade em que a escola está inserida, além da cultura e clientela. A possibilidade do alargamento dessas fronteiras curriculares no processo de ensino-aprendizagem permite aos alunos construir, reconstruir, aperfeiçoar suas noções sobre as mais variadas concepções, ampliando sua percepção como agente de um todo mais amplo e complexo, com diferenças em relação aos demais (SILVA; PORTO, 2012). A BNCC, visando diminuir as desigualdades curriculares regionais propõe uma base comum nacional e uma proposta de educação integral, aquela que contempla os seres humanos em todas as suas dimensões, orienta que além de determinados conhecimentos necessários aos alunos, além disso, deve abranger o desenvolvimento de habilidades que se relacionam com os temas abordados, mas que dialogam com aptidões socioemocionais, que subsidiarão o educando a refletir e agir sobre as demandas complexas que a vida impõe, contribuindo com o pleno exercício da cidadania (BNCC, 2017). Não basta ter o conhecimento, é necessário que se saiba manipula-lo, para que se torne um instrumento útil na vida além dos muros 
escolares; o desenvolvimento intelectual continua sendo um objetivo, mas não mais o único, uma educação integral permeia aptidões sociais, emocionais e culturais.

Reflexo destas mudanças, não restritas apenas a legislações e estudos teóricos, no que tange o ensino de História, contemporaneamente o acréscimo de fontes históricas nas aulas mostra-se como fundamental, pois demonstra um pequeno viés do trabalho do historiador, permite o exercício da observação, a ampliação do conceito de interpretação ao utilizar outros documentos que não apenas textuais, contribuindo na reflexão das informações e conteúdos desses portadores, acresce o conceito de fonte histórica e o modo como se efetiva o fazer histórico, trabalhando diversas habilidades num mesmo exercício. O uso da fonte histórica dentro da sala extrapola esse elemento como apenas mais um recurso didático, uma ferramenta disponível ao professor porque ao propor uma fonte como objeto de análise, que permite interpretações subjetivas conforme as diferentes finalidades em que orientam sua leitura há na verdade uma transposição didática do fazer histórico, já que há uma problematização da fonte, como ocorre com o ofício do historiador (SCHMIDT. In: BITTENCOURT, 2008). Essa abordagem ao passo que aproxima o objeto de estudo dos alunos, contribui para questionamentos que de outra maneira não seriam levados em consideração; há um protagonismo nessa postura ao permitir que se aproxime do trabalho do historiador e consequentemente se participe do fazer a História.

Essa dinamicidade que a disciplina dispõe, seja de fontes ou de interpretações, mostra-se como evidências que nos ajudam a conhecer e reconhecer o nosso patrimônio, a nossa história, que compõe nossa identidade individual e coletiva. Outro ponto que merece destaque é a contextualização do objeto de estudo como fonte primária, situado num tempo e espaço, já que são as indagações do presente que motivam as pesquisas, de algo passado que sofreu mudanças, mas que apresenta algumas permanências. O estudo do meio é uma oportunidade dos discentes explorarem o fato ou o personagem histórico proposto, enquanto lugares de 
memória. Nesse matiz, oportuniza-se a concepção de que algo local pode ser importante não só para o seu entorno, mas para um todo muito maior, já que "o local, fora de um contexto geral, é apenas um fragmento, e o geral, sem o respaldo das realidades locais, é apenas uma abstração; e, neste caso, ambos estarão destituídos de sentido" (NEVES, 1997, p. 22).

Parece-nos, porém, que cada vez mais, ao redor do globo, manifestações e movimentos políticos e sociais têm buscado discutir e investir nas ações afirmadoras das identidades locais e nacionais em detrimento da simples pasteurização cultural. O fortalecimento da cultura local, do resgate da memória e da história local pode ser entendido como uma espécie de antídoto contra a padronização da cultura (FIGUEIRA; MIRANDA, 2012, p. 114).

O ensino de História possibilita o desenvolvimento de inúmeras capacidades cognitivas e sociais que subsidiarão os discentes além do período escolar. Seu estudo deve instigar a curiosidade e estimular a compreensão da realidade; porque além de focar nas mudanças e permanências da humanidade através dos tempos, como uma "Ciência dos homens no tempo" (BLOCH, 2001, p.05), ela atua na construção e consolidação de elementos de valor inestimável aos sujeitos, como no conceito de identidade, memória, patrimônio, cultura, entre outros que ora sejam reconhecidos de modo individual, fazem parte de um todo maior, coletivo. Nesse viés, essa disciplina preenche um papel fundamental no que tange a temática de educação patrimonial, que ajuda no reconhecimento de bens culturais, que possuem valores singulares e plurais para determinados sujeitos e sociedades, oportunizando sua valorização, preservação; auxiliando na construção de "laços de afetividade e de solidariedade com as pessoas e o lugar onde vive" (FIGUEIRA; MIRANDA, 2012, p. 08), nas suas mais variadas práticas sociais.

Estes elementos referenciais com o passar dos tempos vão ganhando significados e valores, enquanto representações e fomentam a base das identidades coletivas (alicerçadas numa memória também coletiva, onde o grupo escolhe o que 
deve ser lembrado e esquecido), que unem diversos indivíduos em torno desses bens culturais comuns a todos, identitários ao constituir traços distintivos e unificadores (FERREIRA; FRANCO, 2013) em relação aos demais. Ainda que haja essa unidade social em torno dessa referência, há de se ressaltar que existem inúmeras diferenças entre os grupos que partilham desse conceito e que formam as individualidades de outros menores ou de seus sujeitos, num contexto mais local, específico. É nesse cenário que surge a essencialidade do docente planejar atividades que contemplem a educação patrimonial pautada na realidade circundante da escola "que visem levar os alunos a conhecer as características da cultura local e a identidade social do grupo no qual está inserido e a desenvolver o sentimento de afetividade pelos bens culturais" (FIGUEIRA; MIRANDA, 2012, p. 72). O conceito de nacionalidade, por exemplo, cabe bem nesse debate em sala de aula, pois somos todos brasileiros, entretanto, há diferenças regionais que nos distinguem uns dos outros, acrescendo nossa pluralidade cultural nas relações sociais, jamais as subtraindo.

Como afirmava Braudel "o presente e o passado esclarecem-se mutuamente, com uma luz recíproca" (1990, p.21), dessa forma, o ensino de História oferece uma perspectiva para a compreensão do presente, que incide da mesma forma na compreensão do passado. O indivíduo pode utilizar seus conhecimentos históricos para entender o mundo em que vive mesmo em momentos que as narrativas históricas não se apresentam evidentes, permitindo sua orientação temporal e a construção de novos significados (SILVA; PORTO, 2012, p. 14).

O ensino de História pode assim contribuir para a formação de cidadãos conscientes da importância da participação social, preocupados em resgatar e respeitar o patrimônio histórico. $\mathrm{O}$ conhecimento e a compreensão da natureza social e individual do ser humano, bem como a consciência da realidade em que vive para o reconhecimento de sua herança cultural e coletiva também devem ser objetivos do ensino da História (BRODBECK, 2012, p. 10). 
É clichê afirmar que os professores querem sempre ensinar seus discentes, mas, além disso, querem que eles se interessem pelo que vão aprender, tornando esse conhecimento significativo (SCARPATO, 2004) por isso a necessidade de aproximar os conteúdos mediados em sala com a realidade do aluno. Ao se aproximar das vivências dos educandos, pode-se demonstrar que a construção da História é repleta de subterfúgios. A existência de um passado é inegável, entretanto, quem escolhe manuseá-lo, é um homem do presente, que para tanto, recorta e dimensiona esse objeto, que passa a representar uma visão contemporânea e individual sobre esse mesmo passado (KARNAL, 2003). Não há como resgatar os fatos em sua totalidade, há lacunas que não conseguem ser preenchidas e que dão as nuances de que não existem verdades absolutas em História, mas visões que são construídas, desconstruídas e reconstruídas através dos historiadores, evitando-se assim as sistematizações totalizantes (CERTEAU, 1982).

\section{Comunidade escolar}

A Escola Estadual Marechal Cândido Rondon localiza-se no Distrito Marechal Rondon, ao lado da rodovia BR-364, no município de Campo Novo do Parecis, Estado de Mato Grosso. Por se tratar de área rural, é considerada como uma escola do campo, atendendo alunos das etapas do Ensino Fundamental ao Ensino Médio. O prédio fora construído há 30 anos, atendendo inicialmente enquanto escola municipal para em 2013 passar para o governo do Estado. O Índice de Desenvolvimento da Educação Básica - IDEB da instituição no ano de 2017 foi de 4,9 pontos frente aos 5,8 pontos da meta nos anos finais do Ensino Fundamental.

A clientela escolar é composta de discentes que moram no referido distrito, além de outros que residem nas fazendas e aldeias ao redor e que dessa forma, utilizam o transporte escolar. Há uma diversidade cultural muito grande e enriquecedora, pois a fundação da cidade e adjacências se deu na década de 70 com a 
vinda de diversas famílias sulistas (paranaenses, catarinenses e gaúchas) e que devido ao trabalho agropecuário dessas propriedades rurais, necessita de modo sazonal da presença de trabalhadores nas mais diversas áreas, oriundos em grande maioria, das regiões norte e nordeste do Brasil. Há muitos casos de pessoas que deixam suas famílias na sua terra natal com o intuito de trabalhar apenas durante uma safra, mas que devido a diversos fatores prósperos decidem fixar residência trazendo-as posteriormente.

Atualmente, atende 156 alunos do Ensino Fundamental I (uma turma de $1^{\circ}$ ano, duas de $2^{\circ}$ ano, duas de $3^{\circ}$ ano, uma de $4^{\circ}$ ano, duas de $5^{\circ}$ ano), 127 do Ensino Fundamental II (duas de $6^{\circ}$ ano, uma de $7^{\circ}$ ano, duas de $8^{\circ}$ ano, duas de $9^{\circ}$ ano) e 40 do Ensino Médio (uma turma para cada ano), distribuídos nos turnos matutino e vespertino. Um ponto que merece destaque é que há 18 indígenas de três diferentes aldeias (Bacaiuval, Sacre II, Utiariti) que frequentam o ambiente, sendo todos da etnia Paresi, que estão matriculados a partir do $6^{\circ}$ ano do Ensino Fundamental II, uma vez que a etapa anterior é realizada nas respectivas aldeias, por professores ou pessoas escolhidas da própria comunidade indígena.

A comunidade circundante à escola possui diversos grupos religiosos (cristãos e não cristãos); desigualdade social bastante evidente há famílias de classe alta e outras em situação de vulnerabilidade. Em termos estruturais, alguns bares, cabarés, uma loja de materiais de construção, algumas oficinas, duas algodoeiras, duas cooperativas de armazenamento de grãos, uma empresa de aviação agrícola, uma praça, um posto de saúde, uma escola municipal, um posto de gasolina, a rodovia já citada. Nas fazendas há a criação de gado, plantio de soja, milho, algodão, que se mostra como a principal oferta de trabalho do local. O que se torna evidente na região é a diferença, seja ela econômica, cultural, religiosa.

\section{Oficina}


Sabe-se que para uma atividade pedagógica exitosa é essencial um planejamento, que quanto mais detalhado, menores são as chances de acontecer algo inesperado que possa obstaculizar sua efetivação. A vida docente por vezes é pautada em mais horas nessa etapa do que necessariamente nas aulas que se consolidam dentro da sala. Para tanto, a base da atividade fora extraída de uma obra que reúne inúmeros modelos didáticos que unem teoria e prática no que tange o ensino de História e apresenta uma entre tantas outras possibilidades que podem ser trabalhadas, considerando as especificidades dos alunos, do tema, da faixa etária. Para referenciar os procedimentos metodológicos da oficina, fora considerado que a mesma deveria abranger o manuseio de fontes primárias e o desenvolvimento de algumas habilidades:

Interpretar imagens;

Desenvolver atividades em grupos;

Identificar a ideia principal em textos;

Realizar pesquisas em fontes diversas;

Coletar e organizar dados e informações (SILVA; PORTO, 2012, p. 38).

Entretanto, é fundamental ressaltar que a escolha do uso de fontes primárias com a referida classe não se tratava de novidade, uma vez que durante todo o ano letivo já haviam trabalhado com fontes em diferentes momentos e que ainda que a oficina almejasse o desenvolvimento de algumas habilidades específicas, elas foram sendo lapidadas em outras aulas, dinamicidade esta que a própria BNCC traz como referência, pois não há como isolar determinadas posturas que se esperam dos discentes sem por vezes, dialogar com outras. Ainda tendo como base o referido documento, pode-se dizer que esta atividade, contemplou de modo indireto, as seis primeiras competências específicas das sete que são apresentadas para o Ensino Fundamental dentro da disciplina de História, que devem ser desenvolvidas ao longo desse período, mas que precisam ser construídas no cotidiano e que não 
encerram em si mesmas a complexidade da formação do sujeito que se espera desenvolver por meio da educação formal.

1. Compreender acontecimentos históricos, relações de poder e processos e mecanismos de transformação e manutenção das estruturas sociais, políticas, econômicas e culturais ao longo do tempo e em diferentes espaços para analisar, posicionar-se e intervir no mundo contemporâneo.

2. Compreender a historicidade no tempo e no espaço, relacionando acontecimentos e processos de transformação e manutenção das estruturas sociais, políticas, econômicas e culturais, bem como problematizar os significados das lógicas de organização cronológica.

3. Elaborar questionamentos, hipóteses, argumentos e proposições em relação a documentos, interpretações e contextos históricos específicos, recorrendo a diferentes linguagens e mídias, exercitando a empatia, o diálogo, a resolução de conflitos, a cooperação e o respeito.

4. Identificar interpretações que expressem visões de diferentes sujeitos, culturas e povos com relação a um mesmo contexto histórico, e posicionar-se criticamente com base em princípios éticos, democráticos, inclusivos, sustentáveis e solidários.

5. Analisar e compreender o movimento de populações e mercadorias no tempo e no espaço e seus significados históricos, levando em conta o respeito e a solidariedade com as diferentes populações.

6. Compreender e problematizar os conceitos e procedimentos norteadores da produção historiográfica (BNCC, 2017, p.402).

É através da junção de temáticas e objetos de conhecimento que se agregam habilidades que se relacionam, se complementam e vão tecendo competências complexas necessárias para a vida dos indivíduos além dos muros escolares. Dentro do que é esperado para $06^{\circ}$ ano entre as unidades temáticas, objetos de conhecimento e habilidades, pode-se afirmar que essa proposta contemplou História: tempo, espaço e formas de registros, Formas de registro da história e da produção do conhecimento histórico e Identificar a gênese da produção do saber histórico e analisar o significado das fontes que originaram determinadas formas de registro em sociedades e épocas distintas (EF06HI02), respectivamente. 
A turma escolhida fora o $6^{\circ}$ ano $\mathrm{B}$, composta por 18 alunos, que durante o ano letivo se sobressaiu em relação às demais nas participações das aulas e na curiosidade sobre as temáticas. O tema escolhido fora a biografia de Marechal Cândido Rondon, devido o nome da escola e do distrito onde ela se situa homenagear-lhe, pois muitos alunos não conhecem a importância deste personagem histórico, que contribuiu com o desenvolvimento do Estado; além dele ter realmente passado pela região, vestígios estes que ainda podem ser vistos numa das aldeias indígenas (alguns discentes residem lá, porém nenhum da classe escolhida) que possui resquícios das linhas telegráficas que motivaram sua vinda na época e a existência em outra localidade também destes mesmos vestígios arqueológicos, que são constantemente visitados por turistas desejosos de conhecer melhor a história da localidade e a presença do Marechal na cidade.

Para o Ensino Fundamental considera-se, antes de tudo, que o aluno precisa estruturar e desenvolver conteúdos e noções básicas do "pensar historicamente", ou seja, buscar trabalhar as relações e noções básicas do ensino de História, relacionadas também a partir do entorno do aluno, ao que ele percebe (BRODBECK, 2012, p. 42).

Para a operacionalização da oficina foram necessários alguns materiais específicos adquiridos anteriormente pela docente: nove envelopes coloridos (tamanho aproximado de $10 \mathrm{~cm} \times 15 \mathrm{~cm}$ ), cola branca, canetinhas, nove folhas de A4. Cada envelope recebeu uma imagem de Marechal Rondon em diferentes momentos de sua vida, bem como uma folha impressa com sete tópicos sobre sua biografia selecionados durante o planejamento (apenas o primeiro tópico e o último eram iguais em todos os textos, respectivamente contemplavam informações sobre o nascimento e a morte do personagem), todas as fontes foram retiradas do arquivo virtual do Centro de Pesquisa e Documentação de História Contemporânea do Brasil - CPDOC da Fundação Getúlio Vargas - FGV. Importante ressaltar que o arquivo original que serviu de fonte textual para a elaboração dos tópicos a ser apresentados 
para os alunos foi adaptado, para que a linguagem se tornasse compreensível aos educandos, considerando sua faixa etária e turma. Os discentes foram estimulados para nesse dia trazerem seus materiais escolares utilizados nas aulas de Artes, como lápis de cor, giz de cera, canetinhas, mas sem a obrigatoriedade de tê-los, porque um dos objetivos era também estimular as interações sociais através da troca e usar o material coletivo disponibilizado pela professora.

As fontes textuais e imagéticas são uma das mais utilizadas com os discentes, considerando o uso dos livros didáticos que estão repletos destas fontes primárias, seja em trechos extraídos e adaptados ou em fotografias e pinturas. Burke em sua obra Testemunha ocular: História e imagem (2004) afirma que as imagens não podem ser consideradas como meros registros de seu tempo e local de origem, mas algo além, como extensões de todo o contexto social em que as produziram, com informações que não foram reveladas nos documentos textuais. Sua produção também envolveu o que merecia ser lembrado e o que seria excluído durante o registro, o que já confere um recorte, uma escolha.

A sala receberia uma configuração diferente da habitual, em formato de semicírculo com duplas de carteiras de modo que entre elas houvesse um espaço para que os alunos pudessem circular para o empréstimo de materiais, se fosse conveniente e necessário, e ainda, próximo ao centro desse formato, seria inserida uma carteira com os materiais coletivos trazidos pela docente para facilitar também o empréstimo.

\section{Entre expectativas e realidade}

A História possui uma ambiguidade que outras disciplinas não apresentam: o nome da sua disciplina e de seu objeto de estudo são iguais (FERREIRA; FRANCO, 2013); os historiadores, por mais que desejem, não conseguem reconstruir todos os fatos em sua totalidade, mas conseguem a cada novo vestígio preencher uma lacuna 
que se encontrava vazia. É essa permanente mudança que torna essa ciência um desafio constante aguardando o historiador se debruçar sobre uma nova fonte, ou sob uma já vista, mas que recebe um novo olhar sob outro viés.

No dia da oficina, ao adentrar na sala, os alunos perceberam que as carteiras ainda estavam na mesma configuração cotidiana, em fileiras, acomodando-se normalmente. Inicialmente, realizada a chamada, todos foram convidados a reorganizar as carteiras e cadeiras dentro das configurações já citadas. Foram orientados a deixar em cima de suas estações de trabalho apenas os materiais que seriam usados, devendo guardar os demais. Para a introdução da temática, fora escrito no quadro branco a palavra "biografia” e questionado o que ela significa (em outros momentos e disciplinas durante o ano a turma já havia sido apresentada a biografias de outros personagens) e por que ela é um instrumento importante para a construção da História, obtendo a participação coletiva, quase unânime nessa etapa; em seguida, abaixo dessa palavra fora escrito "Marechal Rondon" e questionado quem seria ele para, por exemplo, a escola e o distrito levarem seu nome, nesse momento as participações diminuíram e poucos arriscaram comentários de que ele fora um homem importante, para apenas uma aluna comentar que ele havia trabalhado nas linhas telegráficas no Estado e por isso, trouxe desenvolvimento para a região. Como na entrada do distrito há uma estátua dele com algumas informações sobre sua passagem e mastros com as bandeiras do Brasil, de Mato Grosso e Campo Novo do Parecis, os educandos foram questionados mais uma vez se já haviam percebido esse monumento, mas a grande maioria sabia da escultura mas não se atentara até então a descobrir quem seria o personagem; fora orientado para que no retorno para suas casas, os que moram no distrito passassem no local e observassem essa referência.

Após essas discussões foram entregue as folhas em branco e os envelopes para cada dupla e como faltaram dois alunos, sobrou um envelope. Até o final da orientação de como deveriam proceder a ansiedade de descobrir o que havia dentro 
de cada envelope era evidente. A única informação que deveria ser contemplada igualmente entre todas as duplas era de que o título do trabalho seria "Marechal Rondon", ademais a liberdade para escolher como ficaria o resultado final era livre, além de poderem colocar novas informações que desejassem e que fossem ligadas ao tema. Após a abertura dos envelopes, cada dupla leu sua fonte textual e pôde analisar a sua fonte imagética, sendo orientados a não trocar informações e nem mostrar a foto para os demais propositalmente (o que aconteceria durante as trocas de materiais depois). Eles deveriam colar a imagem na folha em qualquer posição, desde que não invertida e inserir sob a forma de pequenos tópicos, o que consideravam mais importante do trecho da biografia que havia no texto, também em qualquer posição, exceto invertido, pois isso dificultaria a visualização dos observadores ao término. Como um envelope ficou sem uma dupla, os alunos sugeriram que a professora também participasse da oficina não só como mediadora, mas produzindo também, de modo individual; para tanto fora utilizada a mesa e cadeira central em que estavam os materiais coletivos. Apesar do planejamento docente, este improviso foi sugestão discente.

Todos se envolveram de forma bastante satisfatória, sem tumultos ou discussões, como às vezes se percebe em atividades que fogem do padrão em que estão acostumados, mas alguns pontos merecem destaque: durante a leitura da biografia surgiram palavras e expressões que os educandos não sabiam o significado, entre elas "alferes", "patrono", "linhas telegráficas" (fora explicado o que era um telégrafo e sua importância para o período), dessa forma, o dicionário de Língua Portuguesa que fica no armário da sala teve que ser usado e não estava no planejamento; uma das duplas desejou desenhar uma bandeira do Estado para complementar seu trabalho e com isso, fora emprestada da Coordenação Escolar a bandeira que é usada no hasteamento durante as horas cívicas que ocorrem geralmente a cada quinze dias. Vale lembrar que as aulas de História nesta classe são geminadas, pois se fossem fragmentadas, haveria a necessidade de trocar com outro 
professor, devido à complexidade do trabalho. Uma das fontes textuais trazia os nomes das etnias indígenas que Rondon teve contato e o grupo que detinha essa informação fez questão de mencionar que na escola há alunos da cultura Paresi. Um discente ficou bastante animado ao saber que seu estado natal, Rondônia, homenageia o Marechal e que antes se chamava Guaporé.

Apesar de a turma ser bastante unida, a configuração da atividade em duplas (que foram escolhidas pelos próprios alunos) com a possibilidade de trocas de materiais durante, fortaleceu ainda mais os vínculos entre os jovens além de contribuir no desenvolvimento de tarefas em grupos, pois alguns ajudaram outras duplas de colegas. Como os educandos já tinham sido apresentados em outros momentos de que o trabalho do historiador é similar ao de um detetive, que colhe pistas para resolver um problema, a História através de seus vestígios arqueológicos que são as fontes (nesse caso um texto biográfico e uma foto) são essenciais para a construção do conhecimento histórico. De modo direto houve interpretação de imagens, identificação da ideia principal no texto e coleta desses dados para aplicação na folha, indiretamente realizaram essa pequena pesquisa dentro do que havia em cada envelope, contemplando os objetivos propostos e já elencados. Seria ambicioso e descabido afirmar que apenas essa oficina contribuiu para o desenvolvimento de determinadas habilidades, mas elas puderam ser aprimoradas com essa atividade, pois o processo de aprendizagem é constante e dinâmico.

Aproximadamente vinte minutos antes do término da aula, a maioria já estava na fase final e cada dupla foi convidada a expor seu trabalho para a classe, podendo caso quisesse, falar sobre a imagem (data, local) e os tópicos elencados; alguns preferiram apenas mostrar e outros foram mais específicos justificando elementos que foram colocados além da fonte textual, como uma dupla que citou o nome do distrito como uma forma de homenagem ao Marechal Rondon (esta informação não estava em nenhuma fonte entregue, propositalmente para ver se alguém se lembraria); as informações e as imagens foram organizadas de modo aleatório nos 
trabalhos, que mesclaram cores (foram usadas canetas, lápis de cor e canetinhas para escrever) e elementos acessórios, como uma dupla que colou as espirais que resultam dos lápis de cor apontados formando flores e outra que reutilizou a folha que continha o texto fazendo dobraduras que foram coladas aleatoriamente no trabalho, embelezando e com o intuito de aguçar a curiosidade de quem observaria. Depois dessa etapa, todos auxiliaram na reorganização da sala, recolhimento do lixo produzido, principalmente dos lápis apontados, devolução dos materiais emprestados. Para finalizar a oficina, foram questionados se gostaram da atividade, recebendo para tanto um sim uníssono; um ponto que merece destaque é que durante a realização da oficina nenhum aluno pediu para se ausentar da sala para ir ao banheiro ou tomar água, como ocorre habitualmente.

Fora sugerido que dividissem com seus familiares alguma informação sobre o Marechal Rondon que haviam visto em sala nesse dia. Os trabalhos foram recolhidos pela professora, como anteriormente já combinado com a Direção Escolar e a classe, as nove salas de aula da escola receberam, cada uma, um exemplar da oficina, que foram fixados nas paredes internas; a turma que fez a atividade teve o trabalho da docente escolhido para isso, para evitar discussões sobre preferência em relação a alguns alunos da classe em detrimento de outros. A ideia de dividir o resultado com as demais salas e de que os alunos comentassem detalhes da biografia do personagem histórico com suas famílias serviu para que esse conhecimento extrapolasse os participantes da oficina, alcançando os demais alunos (as duplas ficaram curiosas para descobrir em qual sala seu trabalho havia sido fixado, instigando o diálogo entre as turmas) e a comunidade escolar, apesar de não poder ser mensurado seu impacto. Antes da efetivação do trabalho, a turma sugeriu que não fosse colocado o nome das duplas nos documentos produzidos, devendo apenas colocar a referência de qual classe se tratava e disciplina e assim foi feito.

Dentre as inúmeras funções que o ensino de História possui seu papel fundamental é "ensinar a refletir e a ler o mundo a partir de uma orientação 
histórica" (FERREIRA; FRANCO, 2013, p. 130) subsidiando os educandos para que se tornem agentes sociais conscientes de suas ações, que transformam a realidade circundante durante o exercício pleno de sua cidadania. Os elementos que constituem o patrimônio histórico-cultural de uma sociedade não se restringem apenas a um acervo composto de obras raras, distantes da realidade e intangíveis para os cidadãos que a compõe, são bens que referenciam identidades e dão significados a conceitos que alicerçam nossas relações sociais, até quando não nos afeiçoamos com eles, vinculando-nos as gerações anteriores e o tempo histórico que as acompanha (ORIÁ. In: BITTENCOURT, 2008). Devido a processos homogeneizantes, oriundos principalmente da globalização, que tende a uniformizar sujeitos, uma forma de valorizar as identidades regionais é revalorizar os referenciais da cultural local, que subsidia a memória dessa comunidade que exerce sua cidadania através de elementos que lhe unem e distinguem das demais.

\section{Referências bibliográficas}

BITTENCOURT, C. (Org.). O saber histórico na sala de aula. São Paulo: Contexto, 2008.

BLOCH, M. A observação histórica. In: Apologia da história ou o ofício do historiador. Rio de Janeiro: Jorge Zahar Ed. 2001.

BRASIL. Base Nacional Comum Curricular (BNCC). Brasília: MEC. 2017. Disponível em: <http://basenacionalcomum.mec.gov.br/> Acesso 26 nov. 2019.

BRASIL. Instituto Nacional de Estudos e Pesquisas Educacionais Anísio Teixeira INEP. Ministério da Educação. Disponível em < http://idebescola.inep.gov.br/ideb/escola/dadosEscola/51066017> Acesso em: 30 nov. de 2019.

BRASIL. Lei n 9.394/96. Lei de Diretrizes e Bases da Educação Nacional. Brasília: Ministério da Educação - Imprensa Oficial, 1996.

BRAUDEL, F. História e Ciências Sociais. Lisboa: Presença, 1990. 
BRODBECK, M. S. L. Vivenciando a história: metodologia de ensino de história. Curitiba: Base Editorial, 2012.

BURKE, P. Testemunha ocular: História e imagem. Bauru: EDUSC, 2004.

CENTRO DE PESQUISA E DOCUMENTAÇÃO DE HISTÓRIA CONTEMPORÂNEA DO BRASIL - CPDOC. Fundação Getúlio Vargas. Disponível em: <http://www.fgv.br/cpdoc/acervo/arquivo>. Acesso em: 20 nov. 2019.

CERTEAU, M. A escrita da história. Tradução de Maria de Lourdes Menezes. Rio de Janeiro: Forense Universitária, 1982.

FERREIRA, M. M.; FRANCO, R. Aprendendo história: reflexão e ensino. Rio de Janeiro: FGV, 2013.

FIGUEIRA, C. A. R.; MIRANDA, L. L. Educação patrimonial no ensino de história nos anos finais do ensino fundamental: conceitos e práticas. São Paulo: Edições SM, 2012. (Somos mestres).

KARNAL, L. (Org.). História na sala de aula: conceitos, práticas e propostas. São Paulo: Contexto, 2003.

LAKATOS, E. M.; MARCONI, M. A. Sociologia Geral. 7. ed. São Paulo: Atlas, 2014.

NEVES, J. História local e construção da identidade social. Revista Saeculum, Universidade Federal da Paraíba, jan./dez. 1997.

RÜSEN, J. Razão histórica: Teoria da história: os fundamentos da ciência histórica. Brasília: UnB, 2001.

SCARPATO, Marta (Org.). Os procedimentos de ensino fazem a aula acontecer. São Paulo: Avercamp, 2004.

SILVA, M. A.; FONSECA, S. G. Ensino de História hoje: errâncias, conquistas e perdas. Revista Brasileira de História, v. 30, nº 60. dez. 2010.

SILVA, M. A.; PORTO, A. Nas trilhas do ensino de história: teoria e prática. Belo Horizonte: Rona, 2012. 